\title{
Mhcj

\section{El uso de Twitter por parte del Gobierno español durante la crisis del ébola}

M HCJ no 6 | Año 2015

Artículo nำ 10 (71)

Páginas 241 a 259

mhjournal.org
D ra. Elba Díaz Cerveró | eldiazc@up.edu.mx

Universidad Panamericana

D ra. Tamara Vázquez Barrio | tamarav@ ceu.es

Universidad CEU San Pablo
Palabras clave

ébola; Twitter; comunicación en situaciones de crisis; análisis de contenido; redes sociales; comunicación gubernamental

Sumario

1. Introducción.

2. La comunicación en situaciones de crisis: definición y características.

3. M etodología.

4. Contextualización del caso: cronología de los hechos.

5. Resultados. 5.1. Número de tweets emitidos. 5.2. Fuentes de los tweets. 5.3. Destinatarios de los Tweets. 5.4. Contenido de los tweets y análisis la reacciones que generan. 5.5. Comentarios de los tweets.

6. Conclusiones y discusión final.

7. Bibliografía.

8. Notas

\section{Resumen}

El 6 de octubre de 2014 se anunciaba a la opinión pública que la auxiliar de enfermería María Teresa Romero Ramos, que había atendido al misionero español Manuel García Viejo contagiado por ébola en Sierra Leona y repatriado a España, daba positivo en la primera prueba que se le hacía para detectar el virus. Era el primer caso de contagio fuera del territorio africano y todos los medios de comunicación del mundo estaban pendientes de la información facilitada por las autoridades españolas. La improvisación y la falta de liderazgo en la primera comparecencia pública de la ministra de Sanidad, Ana Mato, provocaron la sensación de que la situación no estaba bajo control y las especulaciones, los rumores y las opiniones empezaron a circular no solo en los medios periodísticos, sino principalmente a través de Internet y, especialmente, en las redes sociales. Entre las acciones de comunicación adoptadas por el Gobierno se incluyó la creación de una cuenta de Twitter. El objetivo de esta investigación es analizar la cantidad y el tipo de información facilitada y la respuesta que esta cuenta recibe por parte de los internautas. La metodología utilizada es el análisis de contenido cuantitativo y cualitativo. Como muestra se seleccionaron todos los tweets publicados en el perfil oficial @Info_Ebola_Es durante el tiempo que duró la crisis y los comentarios que produjeron. La conclusión general es que la comunicación gubernamental de la crisis a través de la red social habilitada

para este fin adolece de una falta de inmediatez, proactividad y humanización.

\section{Foma de citar este artículo en las bibliografías}

Elba D íaz Cerveró y Tamara Vázquez Barrio (2015): “ El uso de Twitter por parte del G obierno español durante la crisis del ébola”, en Miguel Hernández Communication Journal, no6, páginas 241 a 259. Universidad Miguel Hernández, UMH (Elche-Alicante). Recuperado el __ de de 20 de: [link del artículo en mhjournal.org] 


\section{The use of Twitter by the Spanish Government during the Ebola crisis}

M HC] no 6 | Year 2015

Paper no 10 (71)

Pages 241 to 259

mhjournal.org
D ra. Elba Díaz Cerveró | eldiazc@up.edu.mx

Universidad Panamericana

D ra. Tamara Vázquez Barrio | tamarav@ ceu.es

Universidad CEU San Pablo
Keywords

Ebola, Twitter, crisis communication, content analysis, social networks, government communication

Sumary

1. Introduction.

2. Crisis communication: Definition and features.

3. M ethodology.

4. Context of the analysed case: Chronology of the events.

5. Results. 5.1. Number of tweets. 5.2. Sources of the tweets. 5.3. Addressees of the tweets. 5.4. Content of the tweets and analysis of the reactions generated. 5.5. Comments on the tweets.

6. Conclusions and final discussion.

7. Bibliography.

8. Notes.

\section{Abstract}

The Spanish public opinion learnt on the 6th of October 2014 that the nurse's aid María Teresa Romero Ramos - who had looked after the Spanish missionary Manuel García Viejo, infected with Ebola in Sierra Leona and repatriated to Spain- was positive in the test to detect the virus. It was the first contagion case outside African territory and mass media in the world were paying careful attention to the information given by the Spanish authorities. The improvisation and lack of leadership shown by Ana Mato, Minister of Health, in her first public appearance, gave the impression that the situation was not under control. Speculations, rumours and opinions started to circulate not only in mass media, but mainly on the Internet and especially in social networks. Creating a Twitter account was one of the communication actions adopted by the Government. The objective of this research is to analyse the quality and type of information offered and the response that this account receives from Internet users. The methodology we have used is quantitative and qualitative content analysis. The sample analysed were all tweets published in the profile @ Info_Ebola_Es during the crisis and the comments they received. The general conclusion is that the communication from the Government during the crisis through the social network account created to that end was suffering a lack of immediacy, proactivity and humanization.

\section{How to cite this paper in bibliographies}

Elba D íaz Cerveró y Tamara Vázquez Barrio (2015): “ The use of Twitter by the Spanish G overnment during the Ebola crisis", en Miguel Hernández Communication Journal, ำ6, pages 241 to 259. Universidad Miguel Hernández, UMH (Elche-Alicante). Recuperado el __ de de 20 _- de: [link del artículo en mhjournal.org] 


\section{Introducción}

El 6 de octubre de 2014 se anunciaba a la opinión pública que una de las auxiliares de enfermería del Hospital Carlos III de Madrid, María Teresa Romero Ramos, que había atendido al misionero español Manuel García Viejo contagiado por ébola en Sierra Leona y repatriado a España, daba positivo en la primera prueba que se le hacía para detectar el virus. Era el primer caso de contagio fuera del territorio africano y todos los medios de comunicación del mundo estaban pendientes de la información facilitada por las autoridades españolas.

Ese mismo día, la ministra de Sanidad, Servicios Sociales e Igualdad, Ana Mato, convocó un gabinete de crisis y a las 20.30 horas compareció ante los medios acompañada por la directora general de Salud Pública y otros cinco expertos en enfermedades infecciosas. Después de exponer los hechos, la ministra derivó las respuestas a las preguntas de los periodistas a sus compañeros de mesa, evitando dar cualquier explicación. Esta fue la primera de una serie de decisiones y comparecencias que desataron críticas generalizadas. Según Luis Arroyo, uno de los asesores que gestionó la crisis de la G ripe aviar con el Gobierno de Zapatero en 2005, esa rueda de prensa "fue un ejemplo de lo que no hay que hacer" (El País 10/10/2014). Para Mónica López-Ferrado, periodista científica y coordinadora de ARA ciencia, la mala comunicación de esta crisis se inició con la rueda de prensa de Ana Mato, pero este fue solo el principio de una larga lista de errores ${ }^{1}$. La improvisación y la falta de liderazgo provocaron la sensación de que la situación no estaba bajo control y las especulaciones, los rumores y las opiniones empezaron a circular no solo en los medios periodísticos, sino principalmente a través de Internet y, especialmente, en las redes sociales.

\section{La comunicación en situaciones de crisis: definición y características.}

La comunicación de crisis se ha desarrollado en el ámbito corporativo al amparo de la comunicación estratégica. Marín Calahorro (2005) define crisis como "acontecimientos anormales que afectan al funcionamiento de una entidad y se corresponden con una situación repentina de cambio que hace peligrar la estabilidad de una organización". Muchos otros autores (González Herrero, 1998; Piñuel, 2002; Fink, 2002; Saura, 2005) coinciden al señalar como aspectos característicos de una crisis: 1) que se trata de acontecimientos extraordinarios, situaciones de alerta o graves o cambios inesperados; 2) que son momentos decisivos para la imagen o el normal funcionamiento de una empresa o de una organización y 3) que despiertan un gran interés mediático y público.

La mayoría de los autores también coinciden al determinar tres etapas en el desarrollo de una crisis: la etapa de pre-crisis, la etapa aguda y la etapa de postcrisis. En la primera etapa se detectan los primeros riesgos de que suceda un acontecimiento que pueda derivar o ser el detonante de 
una crisis. En esta etapa deberían evaluarse los posibles riesgos y preparar un plan de crisis. La segunda etapa se corresponde con la crisis propiamente dicha. El acontecimiento de riesgo se ha producido y ha sido recogido por los medios de comunicación. Es el momento de poner en práctica las tareas que se habían planificado con anterioridad. La última fase, la de postcrisis, es posterior al fin de la crisis, cuando todo vuelve a la normalidad, y consiste en evaluar el trabajo realizado y aprender de los errores y aciertos para estar prevenidos ante futuras crisis.

Hay empresas e instituciones que eluden las fases previa y posterior a la crisis. G onzález (1998: 37) señala que "mientras que para algunos la gestión de crisis tan sólo consiste en una serie de medidas y decisiones más o menos urgentes que se han de tomar ante la existencia de un problema, para otros la gestión comienza mucho antes e incluye medidas de previsión y planificación (existiendo, por tanto, gestión de crisis aun cuando nunca llegue a darse una situación de ese tipo)". Actuar sin tener en cuenta las fases previa y posterior constituye un grave error que dificulta la adecuada gestión de la comunicación en esa situación de crisis. La previsión y la preparación son fundamentales para aumentar las posibilidades de obtener buenos resultados.

La planificación es uno de los cinco principios que señala la O MS en su Gúa para planificar la commicacón en casodebrotes epidámios (2008), en la que establece normas de comunicación "basadas en pruebas científicas y sometidas a ensayos, que fomentarán el control rápido de los brotes epidémicos con el menor trastorno posible a la sociedad". Los otros cuatro pilares en los que se debe basar la comunicación en situación de epidemias, según la OMS, son la confianza, los anuncios tempranos, la transparencia y la escucha del público.

El Informe Quiral 10 años titulado Meeiana y Salud en la prensa diaria (1997-2006) también incide en la importancia de la previsión al tiempo que concluye que no es lo que sucede habitualmente en este tipo de situaciones. En el capítulo dedicado al análisis de la comunicación de crisis en los casos de diversas epidemias - reales o supuestas- anunciadas por los medios de comunicación se señala la falta de estrategias de comunicación previas que permitan dar respuesta de un modo adecuado y eficaz a las necesidades informativas que se desatan en estos casos en los que no suele haber tiempo para largas reflexiones. "En estos casos - señala el informe- la percepción de situación de anormalidad contrasta con la falta de respuesta por parte de las autoridades sanitarias, quienes en general lo único que alcanzan a decir es que se están tomando las medidas de control y prevención habituales" (2008: 80).

Como dice Cayón Nieto (2009: 507), que ha estudiado la situación de crisis en el caso de la influenza en México, "durante una crisis sanitaria, la buena gestión de la comunicación es decisiva para construir y mantener la confianza y su credibilidad ante la población [... ] La confianza del público es un elemento clave: si la población no confía en que el Gobierno trabaja por la salud pública y duda de su sinceridad y competencia para manejar la crisis, disminuye el cumplimiento de las medidas recomendadas y los medios distraen su atención de lo esencial para buscar culpables". 


\section{Metodología}

En esta investigación nos vamos a centrar en la red social Twitter como uno de los canales de comunicación habilitados por el Gobierno de España para mantener informada a la sociedad sobre el desarrollo del primer caso de contagio de ébola en el país. El objetivo es analizar la cantidad, el tipo de información facilitada y la respuesta que esta recibe. Todo apunta, y es una de las hipótesis de nuestro trabajo, a que no hubo planificación ni en el tratamiento de los propios hechos del contagio ni en su comunicación, a pesar de que la forma en que se desencadenaron los acontecimientos hubiese permitido estar preparados ante este riesgo. No se trataba de un contagio imprevisible, sino producido en el contexto de la atención sanitaria a un repatriado, lo cual lo hace posible. Además del establecimiento de medidas y protocolos de actuación cuando el contagio ya era un hecho, las autoridades sanitarias debieron haber actuado con proactividad, previniendo en lugar de tener que remediar después.

A la falta de previsión se unía el clima de opinión español. El Gobierno se enfrentaba a esta situación con su reputación enormemente erosionada por los graves casos de corrupción en los que se hallaban inmersos muchos de sus miembros, entre ellos, la Ministra de Sanidad, principal responsable de la gestión de esta crisis. Ana Mato estaba involucrada en aquel momento en el caso Gürtel, en el que se investiga una relación entre Francisco Correa, empresario vinculado al Partido Popular, y una serie de cargos públicos de este partido a los que se les acusa de cohecho y prevaricación, entre otros delitos². Nuestra segunda hipótesis es que esta falta de credibilidad afectó al modo en que los ciudadanos valoraron la gestión de esta crisis de salud pública. Twitter, el medio de información más interactivo de todos los utilizados por el $\mathrm{G}$ obierno en este caso, nos va a permitir valorar este aspecto a través de los comentarios.

De acuerdo al propósito planteado, la metodología utilizada para el desarrollo de esta investigación es el análisis de contenido, tanto cuantitativo como cualitativo. Como muestra se seleccionaron todos los twets publicados en el perfil oficial @Info_Ebola_Es desde su creación, el 14 de octubre de 2014, hasta el 7 de noviembre, fecha en que - al menos hasta el final de esta investigación- la cuenta dejó de tener actividad. La unidad de análisis la ha constituido cada uno de los twetsy las categorías de análisis utilizadas han sido:

1. Fecha en la que se publica el twet.

2. Hora en la que se publica el theet.

3. Fuente del tweet

4. Público objetivo
a. Ciudadanos en general
b. Sanitarios
c. Periodistas
d. Afectados
e. Viajeros

5. № de comentarios

6. Tipo de comentarios
a. Todos favorables
b. Mayoría favorables
c. Mitad y mitad 


\section{d. Mayoría desfavorables \\ e. Todos desfavorables}

Al análisis cuantitativo de las variables arriba señaladas, se ha unido el análisis cualitativo del contenido de cada tweet.

\section{Contextualización del caso: cronología de los hechos.}

21 de septiembre: España repatria al médico español Manuel García Viejo, diagnosticado de ébola en Sierra Leona.

6 de octubre: Teresa Romero, auxiliar de enfermería que había atendido a García Viejo, se convierte en la primera contagiada por ébola fuera de África.

7 de octubre: La sanitaria comienza un tratamiento con anticuerpos de otros infectados. La ministra y el consejero de Sanidad establecen un comité para investigar qué ha podido fallar para se haya producido el contagio.

8 de octubre: Se sacrifica a Excálibur, el perro de Teresa, ante el riesgo de que pudiera haber resultado contagiado. Se producen numerosas reacciones en contra de esta decisión y se convierte en un asunto de especial atención mediática.

10 de octubre: El Consejo de Ministros decide la creación de un comité interministerial presidido por la vicepresidenta, Soraya Sáez de Santamaría, que, con el apoyo de un comité científico, se encargará de la gestión de la crisis. En materia de comunicación, el Comité aprueba un protocolo con el compromiso de suministrar información dos veces al día, además de ir facilitando también la que de forma puntual se vaya produciendo.

9-15 de octubre: Romero se encuentra en situación crítica. Sufre un edema pulmonar.

15 de octubre: La ministra de Sanidad comparece ante la Comisión de Sanidad del Congreso. Por primera vez, deja entrever que pudo haber errores en la gestión.http:/ / politica.elpais.com/ politica/ 2014/ 10/ 15/ actualidad/ 1413400848 422220.html

16 de octubre: Empieza a bajar la carga viral de la auxiliar Teresa Romero.

17 de octubre: Aparecen cuatro posibles casos de ébola, que dan negativo en la primera prueba. Mientras, Romero sigue mejorando.

18 de octubre: Uno de los sospechosos de estar contagiados recibe el alta tras dar negativo en dos pruebas para detectar el ébola. Los otros tres también dan negativo a la primera prueba, pero falta una segunda para confirmar que no tienen el virus. Los análisis realizados a Teresa Romero indican que la carga viral es casi indetectable.

19 de octubre: La última prueba a Romero da negativo. Estos resultados deberán confirmarse en pruebas posteriores, por lo que Teresa Romero continúa en observación.

21 de octubre: Los médicos que atienden a Teresa Romero en el hospital Carlos III de Madrid aseguran que la auxiliar de enfermería ha superado el ébola.

27 de octubre: El marido de Teresa Romero, Javier Limón, y otros 10 pacientes ingresados por su contacto con la auxiliar reciben el alta tras estar 21 días aislados. 
1 de noviembre: Teresa Romero abandona la habitación de aislamiento en el Carlos III tras descartarse la presencia de ébola en el último análisis de sus fluidos corporales.

\section{Resultados}

\subsection{Número de tweets emitidos}

La cuenta de Twitter habilitada por el Gobierno de España para informar sobre la evolución del primer caso de ébola en el país es @ Info_Ebola_Es. Se crea el 14 de octubre, ocho días después de que se declarara como tal el contagio de ébola de la auxiliar de enfermería Teresa Romero y cuatro días más tarde de que la vicepresidenta del Gobierno, Soraya Sáenz de Santamaría, asumiera el mando de esta crisis y constituyera el Comité Especial para la gestión de la enfermedad. Podemos determinar, por tanto, que todos los mensajes son publicados en una fase muy avanzada de la crisis. Desde el día de su nacimiento, el 14 de octubre, @Info_Ebola_Es publica un total de 86 mensajes: 11 su primer día, cuatro el 15 de octubre, 21 el 16, nueve el 17, cuatro el 18, tres el 19, seis el 20, 10 el 21, seis el 22, cinco el 23, uno cada día entre el 24 y el 28, dos el 30, uno el 1 de noviembre y otro el cinco.

Gráfico 1. Número de twetspublicados durante la crisis.

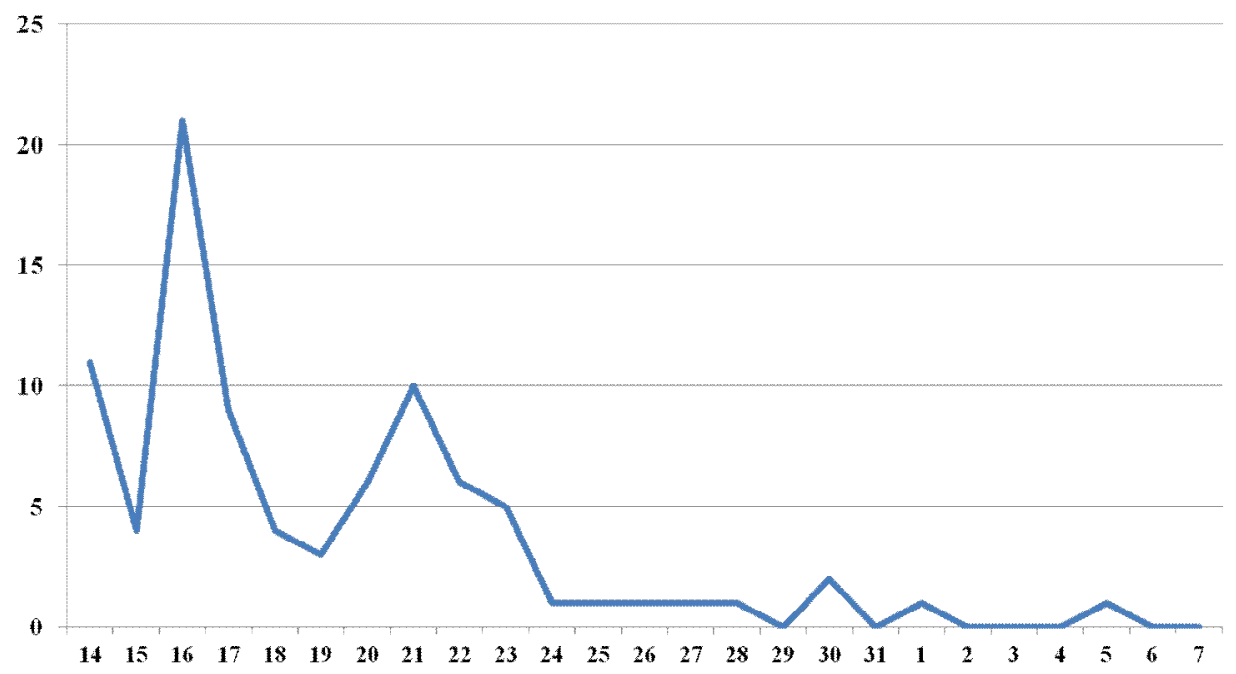

Fuente: Elaboración propia

El primer dato importante es que la cuenta se abre el 14 de octubre, ocho días después de que la primera española fuera contagiada. Según la OMS, las primeras 24 horas de una crisis sanitaria son decisivas para la confianza; hay que ser el primero en anunciarla y hacerlo con empatía (Cayón Nieto, 2009). En este caso, el G obierno no comunicó de la mejor manera los hechos en la rueda de prensa que convocó ese mismo día, y tampoco aprovechó la oportunidad que ofrecen las redes sociales para responder con rapidez y eficacia a la demanda de información que existía. La cuenta oficial de Twitter se puso en marcha muy tarde. 


\subsection{Fuentes de los tweets}

En el 96,8\% de los twets la fuente es algún miembro del Comité de Gestión que son doctores expertos en el tratamiento de la enfermedad. El que más intervine es el director del Centro de Alertas del Ministerio de Sanidad, Fernando Simón, del que se publican un total de 15 twe (14 en los que informa a título individual y uno con Rodríguez). Le sigue Antoni Andreu, director del Instituto de Salud Carlos III, que interviene hasta en cinco tosé Manuel Echevarría, Jefe de Virología del mismo centro y José Ramón Arribas, jefe de la Unidad de Infecciosos del Complejo Hospitalario La Paz-Carlos III, que intervienen tres veces cada uno. Otro de los expertos que se erige en fuente informativa es Sánchez Seco, en cuya información se basan dos twetsy Galdós, experto incorporado de forma tardía al Comité que es la fuente en uno de los twets Al margen de los expertos del comité aparecen otras dos fuentes: la Organización Médica Colegial y la Policía Nacional, que intervienen una vez cada uno.

G ráfico 2. Fuentes de los tweets

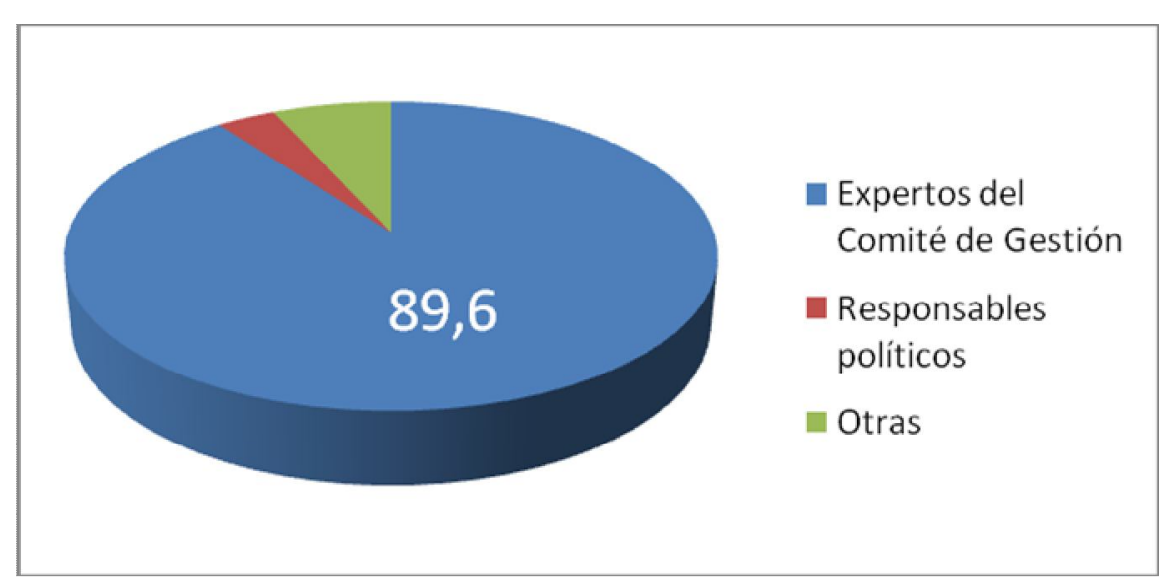

Fuente: Elaboración propia

La voz de los responsables políticos de la gestión de esta crisis no se escucha en la cuenta oficial de Twitter. La vicepresidenta del Gobierno, Soraya Sáenz de Santamaría, constituye la fuente de un solo tweet y la Ministra de Sanidad, Ana Mato, y el Consejero de Sanidad no constituyen la fuente informativa en ninguno de los tweets publicados. Tampoco se da voz en la cuenta de Twitter al D r. Parra, médico que fue el primero en atender a la paciente y que adoptó una postura contraria a las actuaciones del G obierno en el caso del contagio.

\subsection{Destinatarios de los tweets}

De esos 86 mensajes, sólo seis van dirigidos a un público objetivo o segmento concreto; cuatro de ellos van destinados al colectivo de sanitarios y son exactamente aquellos que informan sobre: un plan de formación en bioseguridad, anunciado el mismo 14 de octubre, los protocolos de Sanidad para los profesionales biosanitarios, del 16 de octubre, la Jornada de Protección Civil para colectivos que realizan intervenciones con riesgo de contagio, del día 21, y la recomendación de extremar la prudencia en la retirada de las precauciones, del día 22 del mismo mes. De los 
otros dos mensajes segmentados, uno contiene las recomendaciones para viajeros que visitan las zonas afectadas y el otro es un comunicado del equipo médico en inglés, orientado, por tanto, a usuarios internacionales de Twitter. El resto de mensajes están dirigidos a todos los ciudadanos en general.

Gráfico 3. D estinatarios de los twets

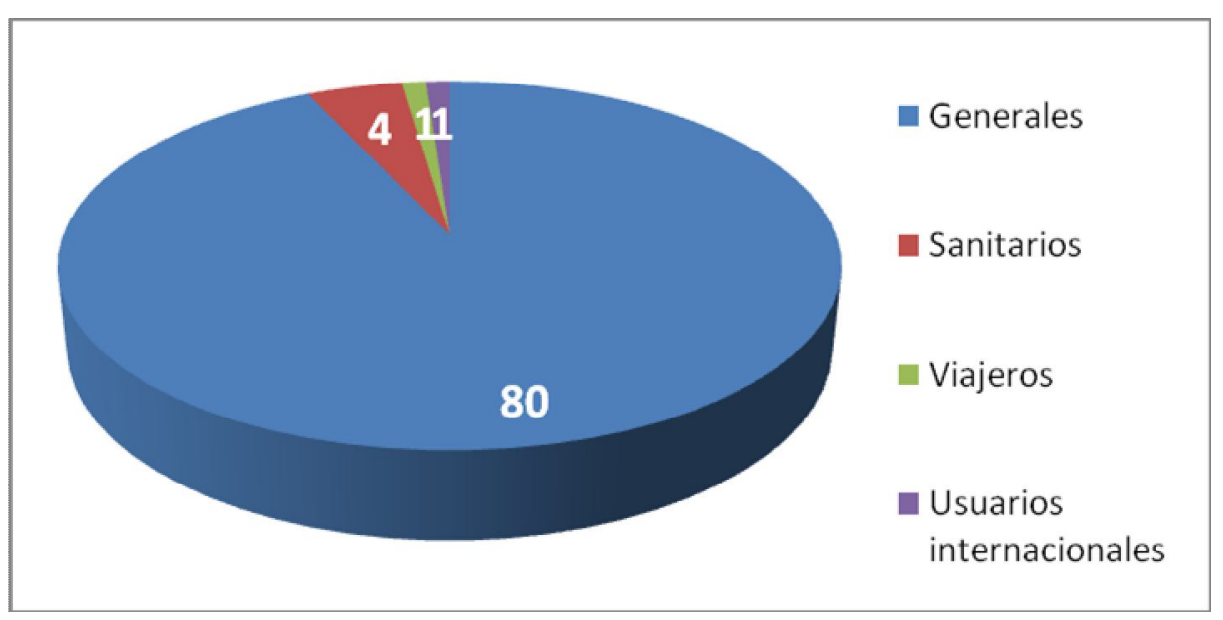

Fuente: Elaboración propia

\subsection{Contenido de los tweets y análisis la reacciones que generan}

El análisis temático de los twets ha consistido en la cuantificación, de acuerdo con una serie de variables preestablecidas, seguido de un análisis más exhaustivo del contenido y de las reacciones que provoca en los seguidores de la cuenta. En lo que respecta al análisis cuantitativo, los resultados son los que se muestran en el gráfico 5 .

Gráfico 4. Contenido de los twetspublicados

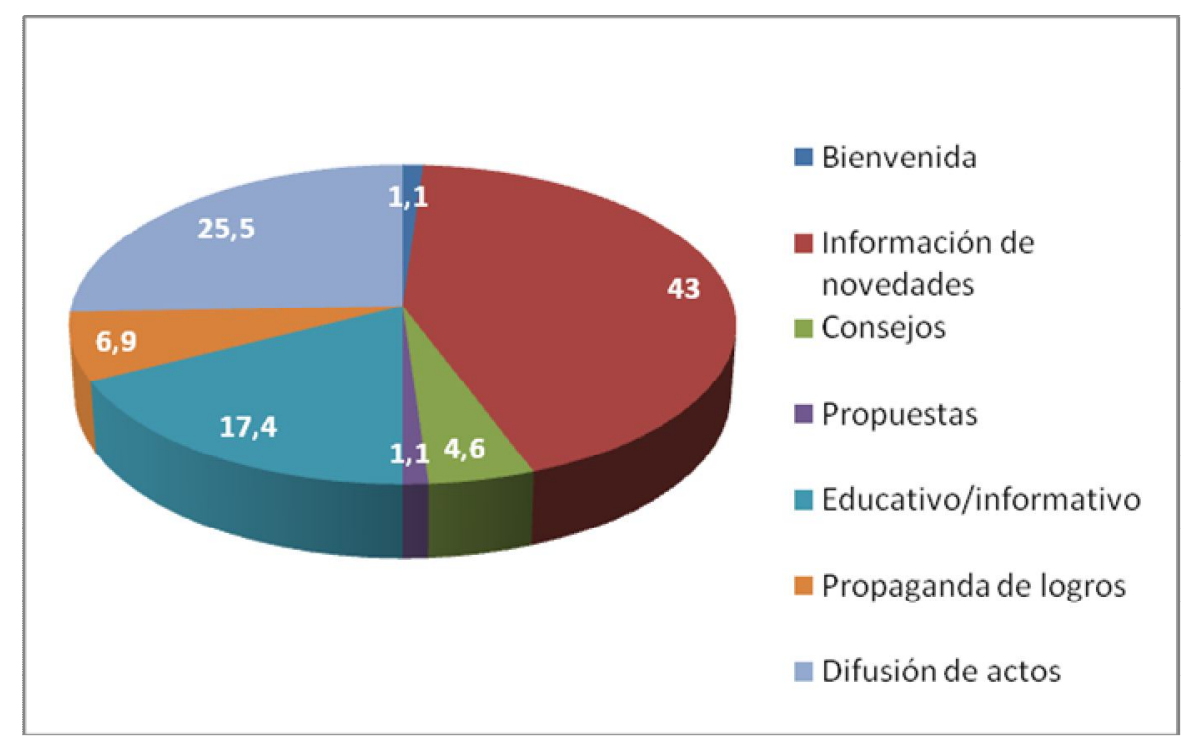

Fuente: Elaboración propia 
El 43\% de los twets publicados informan sobre novedades en relación al caso. Le sigue en segundo lugar la difusión de actos con un 25,5\% y los twets de carácter educativo e informativo que suponen el 17,4\% del total de los mensajes publicados. Muy por debajo de estos porcentajes se sitúan los twets que hacen propaganda de los logros conseguidos (6,9\%), que dan consejos $(4,6 \%)$ o que plantean propuestas $(1,1 \%)$.

El contenido del primer mensaje publicado en la cuenta oficial fue de bienvenida y no aportó ni un solo dato sobre el contagio, de manera que, a la falta de inmediatez, se unió la de información. La suma de ambas es algo que los internautas nunca le perdonarían al Gobiemo, tal como se aprecia en la acogida que le brindan ya desde ese primer mensaje. La cuenta era muy esperada y el tweúne nada menos que 7.000 seguidores, lo que constituye, como se reconoce en uno de los comentarios, un arranque mejor que el de la cuenta del Papa. Las reacciones son de crítica a la gestión de esta crisis por parte de sus responsables políticos. Hay quien reprocha al Ejecutivo que no sea capaz de aplicar protocolos y otro de ellos inserta el hashtag\#Y AeraHora.

El segundo tweet de la cuenta y el primero sobre el contagio propiamente dicho informa: "Acaba de terminar la comparecencia de Antonio Andreu, director del Instituto de Salud Carlos III de Madrid y miembro del Comité Científico". D espués de ocho días sin presencia en la red social, los internautas quieren datos concretos sobre la evolución de la paciente, no mensajes que informen sobre la agenda política en relación a la gestión del caso y que son interpretados como propaganda. Todos los comentarios que genera este twet son desfavorables y algunos emplean términos irónicos, como "genios", para referirse a quienes gestionan esta crisis en el Gobierno por semejante mensaje.

No obstante, estas críticas responden a la impaciencia de los que esperan con interés noticias sobre el caso, ya que las declaraciones de Andreu son desgranadas en cuatro twets posteriores, entre los cuales hay un lapso de entre dos y seis minutos. Dos de esas cuatro aportaciones del experto tratan sobre el estado de la paciente, una sobre la situación clínica y epidemiológica en España y la última sobre el plan de formación en bioseguridad que pretende llevar a cabo la Escuela Nacional de Sanidad. En total, esos cuatro twets generan 44 comentarios que sólo son favorables cuando dan ánimos a la contagiada y la alientan a demandar al Gobierno. Si se refieren específicamente a algún miembro del Ejecutivo, o a la gestión del contagio, las críticas por el manejo del caso, la incredulidad y la desconfianza son constantes. D e la gestión y el Gobierno se dice que son "LAMENTABLES" [sic], y a sus miembros - del Gobierno y del PP- se les llama "ilegales", "inútiles", "mataperros" y "estúpidos". Además, se dice que el PP "es igual a mentira, corrupción y muerte".

Ese mismo 14 de octubre, el Comité Especial de Gestión del Ébola mantiene la primera de sus reuniones y la cuenta de Twitter publica por la tarde, tras las declaraciones de Andreu, el primero de sus comunicados. Esa nota de prensa, así como las otras 16 que se publicarán a continuación a través de enlaces en @Info_Ebola_Es, informan del estado de Teresa Romero y de los posteriores presuntos contagios y son las mismas que aparecen en la web oficial de la Moncloa. 
Todos esos comunicados coinciden al aportar novedades sobre el estado de la paciente y al carecer de un público objetivo específico - es decir, están orientados a los ciudadanos de forma general-. D ifieren en el tipo de comentarios y en los efectos o las reacciones que genera cada uno de ellos.

En este primer caso, el comunicado informa, con el apoyo de un vídeo, de la intervención del director del Instituto de Salud Carlos III, donde está ingresada Teresa Romero. La nota advierte de una leve mejoría de la contagiada, que aun así se encuentra en estado grave, y de que los 15 ingresados por haber mantenido contacto con ella se encuentran asintomáticos. Además, el comunicado reserva un espacio a informar de nuevos cursos de formación preventivos. Casi todos los comentarios que genera el twet son desfavorables y muy críticos con la gestión del Gobierno. La principal crítica es la falta de credibilidad y la desconfianza en el G obierno.

En aras de tranquilizar y quitar miedos respecto a futuros contagios, la siguiente de las publicaciones de la cuenta es un retwet de la Asociación Médica Colegial con un enlace a sus protocolos de actuación. A pesar de que el mensaje reza "Posición de la Asociación Médica Colegial sobre el Sistema Nacional de Salud: tranquilidad y confianza", todos los comentarios que recibe (12) son desfavorables y, entre ellos, la principal crítica es la ineptitud del Gobierno para gestionar esta crisis. El efecto que esto genera es la desconfianza de los usuarios, lo que puede verse reflejado en los adjetivos que le dedican al presidente, al consejero de Sanidad y a los gestores políticos en general. De Rajoy dicen que es un "MENTIROSO" [sic.] y, de Javier Rodríguez, que es "chulo, mediocre y miserable". A los políticos se les llama "caraduras", aunque no se especifica a quiénes exactamente se dedica ese calificativo.

Al final de ese mismo 14 de octubre, @Info_Ebola_Es publica otro comunicado con el aviso de una nueva reunión del Comité y unos datos esquemáticos sobre la evolución de los 16 ingresados. Su estado es exactamente el mismo que el que aparece en el comunicado anterior pero, paradójicamente, en esta ocasión el mensaje es mejor acogido por los usuarios de Twitter, que mayoritariamente se alegran por la noticia y ya no profieren insultos contra los miembros del Gobierno. Sin embargo, al día siguiente, la cuenta anuncia una nueva reunión y, como lo hace sin esperar a que esta finalice -y como había ocurrido el día anterior- los usuarios se muestran impacientes por los resultados y rechazan anuncios sin novedades concretas. La mayoría de los 16 comentarios que genera ese twet de convocatoria son desfavorables y, entre ellos, las principales críticas hacen alusión a que el Gobierno miente y manipula. También son desfavorables la mayoría de comentarios hechos al tweet del comunicado al que la cuenta enlaza tras la reunión. Esa nota de prensa, prácticamente idéntica a las dos anteriores, tiene como principal crítica la ineptitud del Gobierno a la hora de gestionar esta crisis.

No obstante, conviene resaltar que los gestores de la cuenta oficial, aunque publicaron en total 17 previas -a reuniones del comité de gestión, ruedas de prensa 0 apariciones de los expertos en los medios- ya no volverían a caer en el error de informar del final de uno de esos encuentros sin dar datos concretos. Sin embargo, sí aparecen publicados cuatro tweet de difusión del comienzo de 
actos, como por ejemplo "Ha comenzado la reunión del Comité Especial" junto a una foto del encuentro. Este tipo de publicaciones genera reacciones opuestas a partes iguales, de rechazo en los que piensan que la imagen representa simplemente una pose de los políticos y de aceptación por parte de quienes consideran que verdaderamente están trabajando en el caso.

Si aludimos al tipo de mensaje que más se repite, junto a las previas a reuniones, declaraciones y apariciones en medios de expertos, que suman un total de 17 thes encontramos los comunicados del Comité de expertos, que suman también 17. Tres de esos comunicados son emitidos como resultado de la reunión del Comité Especial de Gestión. A excepción de uno, que recoge una lista de consejos, los comunicados informan sobre las novedades en el caso del contagio, que van en tres direcciones: la evolución del estado de Teresa Romero, como principal contagiada, las noticias sobre nuevos posibles contagios y su evolución y las medidas adoptadas por el Comité Especial de G estión del Ébola, generalmente en sus reuniones.

Uno de los aspectos más reseñables es el silencio ante las preguntas y comentarios que se plantean en la cuenta oficial de Twitter. Las autoridades no intervienen para contestar ni a uno solo de los comentarios de los usuarios y en su lugar crean el hashtag\#ÉbolaRespuestas, en el que plantean preguntas frecuentes y respuestas a esas preguntas. Esta información se encuentra también disponible en la web oficial, donde está más completa, ya que a través de la cuenta de twitter tan sólo se publican tres mensajes de este tipo los días 21 y 22 de octubre. Las preguntas concretas que se recogen en estos twets son: “¿Puede el virus Ébola establecer infecciones crónicas en un paciente?”, “¿Cuándo se puede considerar que un contagiado se ha curado de la enfermedad?” y “'Puede contagiarse el ébola en lugares públicos?”. Los comentarios a estos tweets indican que, como en los casos anteriores, esas cuestiones quedan sin resolver por los gestores de la cuenta y son los propios usuarios quienes suplen la labor del Gobierno contestándose unos a otros.

Otro de los aspectos llamativos de la comunicación llevada a cabo por los responsables políticos de esta crisis a través de la red social twitter es la escasa compasión que se muestra hacia la contagiada. Así, mientras que los comentarios de apoyo y aliento a Teresa Romero son frecuentes entre los comentarios publicados por ciudadanos anónimos, la cuenta oficial publica un solo tweet de alegría por su evolución en el que se puede leer: "Felices por la excelente noticia acerca de Teresa Romero". Los expertos en comunicaciones de crisis, especialmente los que lo son en crisis relacionadas con pandemias y el ámbito sanitario, señalan que, de cara a la audiencia, es muy importante mostrar empatía, reconociendo que las muertes o la enfermedad son una tragedia y evitando el lenguaje distante. También indican que es necesario atender las necesidades particulares de comunicación (Cayón Nieto, 2009). En este caso, ese lacónico y único mensaje que las autoridades dedican a la principal víctima del contagio y la falta de respuesta e interacción con el resto de usuarios muestra que en la cuenta de Twitter la comunicación oficial no sigue ninguna de esas dos recomendaciones. Tampoco hace mención alguna la cuenta al hecho de haber tenido que sacrificar a Excálibur, el perro de Teresa Romero, habiéndose convertido este hecho en uno de los más comentados en el transcurso de esta crisis. 


\subsection{Comentarios a los tweets}

De los 86 twata, 24 generan comentarios mayoritariamente desfavorables, 18 mayoritariamente favorables y 10 absolutamente desfavorables. Hay seis que generan la mitad de los comentarios favorables y la otra mitad desfavorables y 4 que generan comentarios neutros, que no se pueden evaluar en un sentido u otro. Los 24 twetsrestantes no generan interactividad con los usuarios de la red social. No hay ni un solo tweet que genere todos sus comentarios favorables.

Gráfico 5. Comentarios publicados en la cuenta oficial de Twitter.

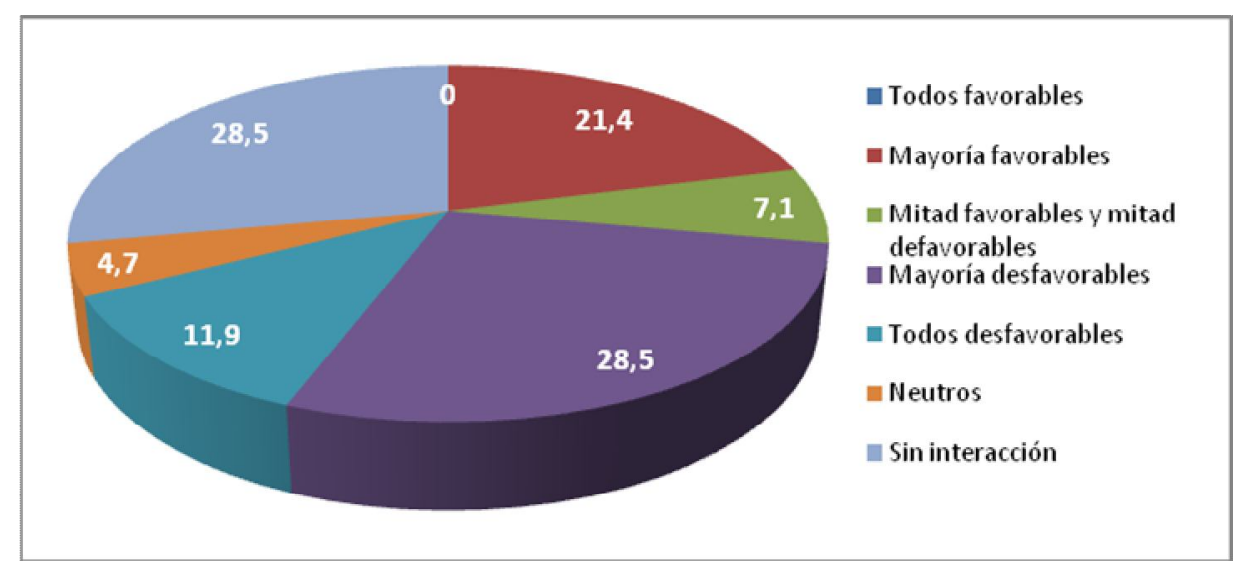

Fuente: Elaboración propia

Como se observa en el gráfico anterior, predominan los comentarios desfavorables. Las principales críticas realizadas por los usuarios lo son a la gestión política de esta situación de crisis y la falta de transparencia, sobre todo por parte de la Ministra. Todo ello genera, como principal efecto, la sensación de ineptitud, la incredulidad y la desconfianza en el Gobierno. También se puede concluir que parte de la indignación que se manifiesta a través de insultos hacia los responsables de la crisis. D oce de los 62 twe oficiales que generan comentarios provocan hasta un total de 34 improperios. Sin ánimo de ser exhaustivos, a los políticos se les llama "golfos" y a Mariano Rajoy se le dice que miente "como gallego", que está "enfermito" y también se le increpa: "Tas acabado [sic.], qué poco te queda, eres cadáver político". Dirigiéndose al Partido Popular, se puede leer "piara de corruptos saqueadores de la hacienda pública, rateros!!!" y a los políticos que han gestionado la crisis se les dice que son "tremendamente prepotentes y nefastos". D e la cuenta se dice que "es un chiste, fue un chiste y será un chiste", así como que "la comunicación no es el punto fuerte de este G obierno, si es que tiene alguno".

No todos los gestores políticos de la crisis son apreciados del mismo modo por parte de los usuarios. Mientras que no se han encontrado insultos ni críticas directas hacia la vicepresidenta del Gobierno, Sáenz de Santamaría, son abundantes los destinados a la Ministra de Sanidad, al presidente del Gobierno y al Consejero de Sanidad. Los insultos que se refieren a la Ministra de Sanidad castigan su incompetencia para gestionar esta crisis. Los que se dirigen a Rajoy le auguran un final próximo como Presidente del Gobierno y, en el caso de consejero de Sanidad, Javier 
Rodríguez, las críticas en forma de insultos señalan su prepotencia, en alusión a que acusó a la contagiada de haber mentido sobre sus síntomas y no haber aplicado correctamente el protocolo.

En general, los insultos constituyen las críticas más duras a la gestión del Gobierno y a sus propios miembros que, como decíamos, no sólo han tenido que luchar contra una reputación dañada por esta situación de crisis, sino que ya se enfrentaban a ella con una imagen realmente desgastada y castigada por la corrupción que, entre otros, afectaba a la figura de la Ministra de Sanidad, Ana Mato, inmersa en la 'trama Gürtel'. Al cierre de esta investigación, la Ministra de Sanidad dimitía, motu propio u obligada por Rajoy, tras su citación judicial en ese caso de corrupción. Días más tarde, el 2 de diciembre, se conocía que Alfonso Alonso asumía esa cartera.

\section{Conclusiones y discusión final}

La primera conclusión a la que llega nuestro análisis es la falta de inmediatez del Gobierno a la hora de poner en marcha la cuenta de Twitter diseñada especialmente para la comunicación de crisis que supuso el primer contagio de Ébola en España. Ello fue acompañado de una falta de proactividad en sus primeros mensajes, al anunciar finales de comparecencias sin anticipar el contenido de las principales declaraciones. Todo ello, después de ocho días sin presencia en la red social, dio la imagen de un Gobierno lento y poco resuelto a la hora de comunicar, sobre todo en una plataforma donde, justamente, lo que prima, se fomenta y se valora es la inmediatez.

Esa falta de proactividad estaba, en realidad, encubriendo otra de transparencia. El Gobierno tardó tanto tiempo en lanzar la cuenta porque en ese tiempo ocurrieron algunos sucesos desagradables y difíciles de comunicar, como el sacrificio del perro de la contagiada; el hecho de que el Consejero de Sanidad la acusase de haber mentido y de otras negligencias en la aplicación del protocolo; las críticas de Juan Manuel Parra, el doctor que atendió a la enferma, a los responsables de la crisis por su mala gestión... Aun así, todo ello no debería haber contribuido a generar más confusión y la cuenta podría haberse lanzado antes, por ejemplo, el día en que se creó el Comité Especial de Gestión, el 10 de octubre. Cuanto más tardaba el Gobierno en pronunciarse en Twitter, más ansiosos y reacios se mostrarían los usuarios a sus primeros mensajes.

Los comunicados tipo previa o convocatoria, tan rutinarias en las relaciones entre las instituciones y la prensa tradicional, no parecen útiles cuando se trasladan a Twitter en una situación de crisis. Tampoco en este caso -y eso que sí son más propios de las redes sociales- los que se emiten mientras se celebra un acto tienen buena acogida entre los usuarios, ya que lo que estos desean son datos concretos, con la implicación directa de los responsables políticos de esta crisis. Todo lo demás, como las fotos tomadas durante la reunión o la de los expertos miembros del Comité leyendo los twets a muchos les suena a pose y a ninguno satisface las altas de expectativas generadas durante todo el tiempo en que no se ha dado información concreta y suficiente. 
En relación con esto, lo cierto es que los datos que proporciona el Gobierno muchas veces generan preguntas de los usuarios que siempre quedan sin contestar por parte de los responsables políticos o de los expertos del Comité Especial. Ni los representantes políticos ni los expertos contestan nunca a los comentarios de los internautas. En ese sentido, se da la razón a quienes consideran que unos y otros actúan de cara a la galería porque, por muchos mensajes que lea un doctor -y así aparezca retratado en Twitter-, eso no sirve de nada si deja sin contestar las preguntas y sin solucionar las dudas que ellos plantean como retroalimentación al twet oficial.

Puesto que no hay respuestas oficiales, son los propios internautas los que se responden entre sí. Una parte de las cuestiones que surgen parece ser contestada con el conocimiento propio de quienes supuestamente más saben sobre el tema. La otra es respondida a través del enlace a páginas externas de mayor o menor confiabilidad. Cada vez que esto último sucede, el Gobierno desaprovecha una oportunidad para poner en valor sus propios recursos, evitar rumores y mostrar autoridad a la hora de informar y aclarar cuestiones que generan duda entre los ciudadanos. En lugar de aprovechar para erigirse en fuente confiable y única en la materia, obliga a los ciudadanos a que se informen a través de vías alternativas. Pero aún peor es lo anterior, es decir, el hecho de que sean los propios internautas quienes se contesten a sus propias dudas no sólo genera la sensación de desamparo entre quienes preguntan y no obtienen respuesta del Gobierno, sino que resulta peligroso porque no se sabe a ciencia cierta cuál es el nivel de conocimiento o la autoridad real de quien contesta a esas cuestiones de carácter técnico. Puesto que los comentarios son públicos y a simple vista se desconoce su autor, los usuarios podrían estar dando validez a una fuente que no la mereciera en absoluto.

En realidad, los responsables políticos no participan, no sólo porque no contesten a los comentarios que suscitan los tedsinstitucionales, sino porque ni siquiera constituyen - salvo en un solo caso- la fuente de información de esos mensajes oficiales. El 17 de octubre la cuenta publica un twet en el que la Vicepresidenta informa en rueda de prensa del resultado negativo de las personas en observación. A excepción de ese mensaje 0, lo que es lo mismo, en 85 de 86 mensajes, los principales responsables políticos de esta crisis son absolutamente invisibles a ojos de los internautas.

El nivel de interactividad de los twets oficiales es alto, ya que el $72 \%$ de los mensajes oficiales genera comentarios y, a pesar de que no se aprecian tendencias que nos permitan inferir una evolución hacia mayor apoyo o beligerancia, sí podemos decir que el Gobierno no consigue lograr que ni uno solo de sus twets genere una respuesta del público totalmente positiva. La sensación de ineptitud y la falta de previsión que se le achacan al Ejecutivo constituyen un binomio que, unido a la imagen de corrupción generalizada en todas las esferas gubernamentales, fomenta la desconfianza en la comunicación institucional a través de Twitter como principal efecto entre los ciudadanos que utilizan esta red social para informarse de la evolución del contagio. 
Ni siquiera cuando esa evolución es positiva y Teresa Romero va estando cada vez mejor, se reconoce una buena labor por parte del Gobierno en la totalidad de los comentarios. Llegados a este punto, las voces se dividen entre las que sí reconocen que los avances se deben a que el Ejecutivo ha actuado con diligencia y las de quienes piensan que todo el mérito lo tienen los sanitarios y empleados de la sanidad pública, idea esta muy en la línea de lo manifestado también en Twitter por Juan Manuel Parra. Y aquí es donde se percibe especialmente cómo los mensajes de apoyo o rechazo tienen que ver con la mayor o menor sintonía con la política del PP.

Por el número de twets publicados, y derivado de lo anterior, se puede decir que el Gobierno cumple con la parte del protocolo de comunicación en la que estipulaba que informaría puntualmente al menos dos veces al día y, de hecho, los días en los que publica un solo twet son todos posteriores a la completa recuperación de Teresa Moreno. En realidad, este dato podría abrir el debate de si es o no útil marcarse un número de informaciones diario. El hecho de que los primeros días de ingreso de la contagiada veamos twe que enlazan con comunicados casi idénticos nos puede llevar a recordar la premisa periodística que indica que toda información ha de contener un elemento de novedad. En todo caso, y puesto que las crisis son situaciones imprevistas, la información debería proporcionarse tan pronto como se tiene, después de ser contrastada y sin obsesionarse por una frecuencia determinada de antemano.

Siendo estrictos, y dejando a un lado lo reiterativo en el contenido de algunos comunicados oficiales, 86 twetsparecen suficientes y, por lo tanto, no podríamos achacar al G obierno una mala gestión comunicativa desde el punto de vista cuantitativo. Sin embargo, de todo lo resaltado hasta el momento sí se concluye que la comunicación dista bastante de la idónea en lo cualitativo. Retomando la idea de que ni la autoría ni las fuentes de los twets oficiales está constituida por ninguno de los representantes políticos de este caso, esto podría ser tenido en cuenta como una debilidad de la gestión.

A juzgar por las apariciones de la Ministra que, de hecho, dimitió, muchos dirán que ha sido preferible que no se haya manifestado en las redes sociales. En este sentido, entonces, cabría sentarse a repensar el futuro de la política y del grado de profesionalización que deberín tener, sobre su ámbito, cartera, ministerio o consejería, quienes nos gobiernan. Pero eso tampoco tendría mucho sentido si tenemos en cuenta que el Consejero de Sanidad de la Comunidad de Madrid, Francisco Javier Rodríguez, sí es doctor en Medicina y, sin embargo, cometió errores flagrantes en la gestión y la comunicación del contagio. Podríamos apelar entonces, en ambos casos, a una mayor capacitación de los políticos en materia comunicativa de crisis pero, puesto que eso excedería a las pretensiones de este trabajo, nos quedaremos en la propuesta de una mayor humanización, proactividad e inmediatez por parte de los expertos y de los políticos a la hora de dar respuesta a los ciudadanos.

En realidad, para lograr una correcta y rápida respuesta a los internautas habría bastado con que uno de los gestores de la cuenta oficial de Twitter hubiera tenido línea directa con los expertos para canalizar adecuadamente cada una de esas dudas -que no eran tantas ni tan complicadas- y 
dar una respuesta pronta a los ciudadanos. Así, además de conseguir esa inmediatez, se habría evitado que usuarios anónimos y sin una acreditación constatada de sus conocimientos respondieran a esas cuestiones.

Con todo, ese tampoco es el peor aspecto de la comunicación de esta crisis. De lo que más adolecen los mensajes institucionales de Twitter es de una gran falta de empatía con la víctima del contagio, algo que sí muestran los ciudadanos en los comentarios de aliento que le dedican y lo que la cuenta manifiesta en uno solo de los 86 twets que publica. De los otros 85, con su tono distante, se desprende una sensación de asepsia y frialdad absoluta hacia Teresa Romero. De manera que, una vez más, el G obierno desaprovecha la ocasión para mostrarse cercano, lo que le habría reportado, no solo una mayor adhesión en forma de comentarios favorables a sus comunicados, sino también, la impresión de que el Ejecutivo, con sus defectos y errores, está formado por personas de gran compromiso y valor humano.

\section{Bibliografía}

G onzález, A. (1998). Markeingpreventiva la commicación decisisenla empresa Barcelona: Bosch.

Nieto, Arantxa Cayón (2009). Comunicación de crisis en el marco de la preparación ante la pandemia de influenza en México: revisión de conceptos y estrategias. Reista deadministracón sanitaia sigoXXI, 7(3), 501-516.

Revuelta, G . y Semir, V. de (2008). InfomeQuiral 1997-2006. Meelianay saludenla prensa diana Análisis de10 años deinfomación sanitania en El País, El Mundo, ABC, LaV anguardiay El Peióóicode Catalunya. Barcelona: UPF.

Sustein, Cass R. (2010). Rumordoǵa. Cómosedifundenlas falsedades, por quémoslas ceemosyquésepuede hacer contra dlas Barcelona: D ebate.

Pinedo, Arturo; Navarro, Joan; G oicoechea, Cristina (2012). Rumores, reputación y situaciones de crisis. d+i LlarenteyCuenca Recuperado de http:/ / www.blogdeasuntospublicos.com/ wpcontent/ uploads/2012/ 12/ articulo1.jpg

Piñuel, José Luis (2002). La comunicación corporativa de la gestión de Crisis. Revista Commicaaón yPsictenia, 2, pp. 5-34.

Saura, P. (2005). La gestiónyla commicaión decisis en e setor dela alimentacóny ybdidas d análisis de caso «pañd, la refeenia a Europaya EE.UU., d moddoidæal preentivoC.I.C.L.E. Madrid: UPC. 
Marín Calahorro, F. (2005). G estión técnica y de la comunicación en situaciones especiales. Crisis, emergencias y negociación. Madrid: Fragua O MS (2008): Guía de la O rganización Mundial de la Salud para planificar la comunicación en caso de brotes epidémicos. Recuperado de http:/ / whqlibdoc.who.int/ publications/ 2009/ 9789243597447_spa.pdf

Fink, S. (2002). CrisisManagenet: Planningfor theineitable O hio: Backinprint.com Edition.

Viejo, M. (2014). Los cinco errores de comunicación institucional en la crisis del ébola. El País 10/ 10/ 2014. Recuperado de http:/ / politica.elpais.com/ politica/ 2014/ 10/ 09/ actualidad/ 1412872730_989674.html

Costa, C. (2010): "Crisis de salud pública. El derecho de los ciudadanos a estar informados", Diálogos dela Commicaión N82, SEPTIEMBRE - D ICIEMBRE 2010, pp. 1-6.

\section{Notas}

1. Declaraciones realizadas en la mesa redonda Los agujeros negros de la comunicación en la crisis del ébola que se ha celebrado en el Col· legi de Periodistes de Catalunya. Información sobre ese acto disponible en: http://cristinaaced.com/blog/2014/10/17/como-agravar-una-crisis-sanitaria-con-una-mala-comunicacion-el-caso-delebola-en-espana/

2. De hecho, solo unos días después de que se diese por finalizada la crisis del ébola, el magistrado de la Audiencia Nacional, Pablo Ruz, la señaló como partícipe a título lucrativo de los delitos supuestamente cometidos por su exmarido en la trama Gürtel, lo que precipitó su dimisión. 


\section{(c) (i) (2) \\ Licencia Creative Commons \\ Miguel Hernández Communication Journal \\ mhcj.es}

\section{Forma de citar este artículo en las bibliografías}

Elba D íaz Cerveró y Tamara Vázquez Barrio (2015): “ El uso de Twitter por parte del G obierno español durante la crisis del ébola”, en Miguel Hernández Communication Journal, nํ6, páginas 241 a 259. Universidad Miguel Hernández, UMH (Elche-Alicante). Recuperado el _- de de $20_{--}$de: [link del artículo en mhjournal.org] 